\title{
Peer Tutoring - Assisted Instruction, Parent Supportiveness and Student Locus of Control - as Determinants of Academic Achievement in Senior Secondary School Mathematics
}

\author{
Onabanjo, I. Oluyemi \\ Department of Educational Foundations and Management, Faculty of Education \\ Olabisi Onabanjo University, Ago-Iwoye, Ogun State, Nigeria \\ E-mail Iyaboonabanjo@Yohoo.Co.Uk \\ and \\ Okpala, P.N. \\ Institute of Education, University of Ibadan \\ Ibadan, Oyo State, Nigeria
}

\begin{abstract}
The study investigated the effect of peer tutoring-assisted instruction, parent supportiveness and students locus of control on achievement in Senior Secondary Mathematics. It adopted a non-randomized pretest posttest control group design in a quasi experimental setting. It involves 300 senior secondary II students from six coeducational secondary schools in Odogbolu and Ijebu - Ode Local Government Areas of Ogun State Nigeria. The data collected were analysed using analysis of Covariance (ANCOVA). The findings revealed that there was significant main effect of treatment (peer tutoring) on mathematics achievement, it also revealed a significant interaction effect of treatment and parent supportiveness on achievement in mathematics. The three way interaction was founded not to be significant. The implication and recommendations were made.
\end{abstract}

\section{Introduction}

The Nigerian society is aware of the importance and tremendous application of scientific knowledge. It is well known that without science, there is no technology and without mathematics there is no science (Fajamidagba, 1996). Science Technology and Mathematics (STM) are important and mutually dependent therefore, there is need to embed mathematical, scientific and technological knowledge in everyday life.

Mathematics has been highlighted as a very important subject which is experiencing difficulties and the state of mathematics in Nigeria is a matter of concern. The low levels of attainment of students in mathematics at every segment of educational system have given mathematics and even mathematics educators a high level of concern which is so because of the universally held assumption of the importance of the subject to the growth and development of mankind (Akinsola, 1999).

A lot of research efforts have been focused on identifying factors that inhibit the learning of mathematics and against students' performance in senior secondary mathematics. Inadequate number of qualified and interested 
teachers have been identified as one of the problems, gender stereotyping, motivation, Lecture method have been highlighted as part of the problems. Adepoju (1991) describes the approach used by many teachers of mathematics as one which does not give room for students to develop their intuition, imagination and creative abilities.

There are also indications the parents constitute a powerful body that can influence the overall performance of the child and that the traditional approach to teaching mathematics (the lecture method) has failed to deal effectively with the problems of individual differences in mathematics. It has also failed to provide for the students' appreciation and understanding of learning as a continuing aspect of modern learning theory which stresses students' active involvement in the teaching learning process. There is therefore need to search for more effective instructional strategies that are likely to improve achievement in senior secondary mathematics. Such strategies perhaps, include cooperative based learning instructional strategies which have been found to improve science learning outcomes (Oebukonla, 1984; Iroegbu, 1998; Slavin 1990) and that peer tutoring is a type of cooperative based learning institutional strategy.

Peer tutoring is a personalized system of instruction which is learner rather than teacher oriented, it emphasizes active students participation in the learning process. It is an individualized attention to a learner, the tutee, by a person of similar status (e.g. with respect to age, educational experience etc.) who serves as the tutor. Studies have revealed that peer tutoring as an instructional strategy benefits both the students being tutored and the tutor, although the tutor is associated with greater cognitive gains than students being taught (Annis, 1982, Bargh and Schul 1980; lambiotte et. al., 1987).

This study also focused on the effect of parent supportiveness, students' locus of control and gender on the achievement of students in senior secondary mathematics. Parent supportiveness is the support given to the students by their parents and these supports include the obligation of parents toward their children (i.e. providing food, clothing, shelter, materials necessary for learning as well as parents' involvement in regular checks of what is being taught in school) and the provision of direct instruction to the students when necessary. Students' locus of control can be expressed as the extent to which a person believed that reinforcement was contingent upon ones own behaviour (internal). Also, considering the fact that gender stereotyping is still very much in Nigerian learning environment (Onocha, Okpala and Offorma, 1995) the study also sought to evaluate the effects of gender on students performance in senior secondary mathematics.

It is against this background that this study was designed to assess peer tutoring-assisted instruction, (treatment), parent supportiveness, students' locus of control as determinants of achievement in senior secondary mathematics. 


\section{Research Hypotheses}

Specifically, the study sought to test the following hypotheses:

(1) Mathematics achievement of

a. students exposed to peer tutoring-assisted instruction (treatment) will not be significantly higher than that of students in the control group.

b. students of high parent supportiveness is not significantly higher than that of student of low supportiveness.

c. male students is not significantly higher than that of female.

d. students who are internal is not significantly higher than their counterparts who are external.

(2) Achievement in Mathematics is not significantly affected by interaction of:

a. treatment and parent supportiveness.

b. treatment and locus of control.

c. treatment and gender.

(3) Achievement in Mathematics is not significantly affect by interaction of:

a. treatment, parent supportiveness and locus of control.

b. treatment, parent supportiveness and gender.

c. treatment, parent supportiveness, locus of control and gender.

\section{Methodology}

\section{Design}

The study made use of a pretest-posttest non-randomized control group design in a quasi-experimental setting which the treatment (as three levels) was crossed with parent supportiveness (two levels), student locus of control (as two levels) and gender (at two levels).

\section{Sample}

The sample consisted of 300 senior secondary school two (SSII) students (137 female and 163 male) from six randomly selected co-educational secondary areas of Ogun State Nigeria. The students were exposed to three levels (101 for peer tutoring conventional teaching, 99 for peer tutoring alone and 100 for conventional teaching alone).

\section{Instrumentation}

The study made use of three valid and reliable instruments. The Mathematics achievement test (MAT) (KR. 20=0.081), Parent Supportiveness Questionnaire (PSQ) with inter-rater value of 0.85 and student locus of control scale (LOC) with reliability coefficient of 0.79 . 


\section{Procedure}

The Mathematics teachers of the participating schools were first trained on how to use the treatment package. These teachers then made the students to respond to the three instruments: the LOCS, the PSQ and MAT. The LOCS scores were used in classifying the students into two locus of control grouping: internal and external, the PSQ scores served the purpose of classifying the students into two groups of parent supportiveness. Low and High. The MAT scores served as pre-test (covariate scores). After this, the teachers provided the treatment conditions to the experimental and control groups (simple random sampling was used to decide the specific treatment provided for each intact class of a selected school). The treatment lasted for six weeks at the end of which the teachers administered the MAT as posttest.

The three treatment groups were as follows:

1. Experimental Group 1: The treatment in this group consisted of teacher instruction and peer tutoring. First the students were exposed to teacher instruction, which consisted of the four procedural steps: preamble, exposition, remediation and summary. Next, the group were exposed to peer-tutoring and this involved peering the students in groups of four with one of them serving as the tutor. The teacher requested that peer tutoring be used to re-study the lesson taught (under teacher supervision).

2. Experimental Group 2: The treatment in this group consisted peer tutoring alone. The students were peered in groups of four with one of them serving as the tutor. The peer tutored group studied the lesson topic under the teacher's supervision.

3. Control Group: The treatment in this group consisted of the normal conventional method of teaching (i.e. teacher instruction alone)

\section{Data Analysis}

The posttest achievement scores were subjected to analysis of covariance using pretest scores as covariates. The Scheffe test and graphical illustrations were employed as post-hoc measures to disentangle interactions effects where necessary.

\section{Results}

Table 1 shows data from the analysis of covariance of mathematics achievement using pre-test achievement scores as covariate. The table shows significant main effect of treatment $\left(\mathrm{F}_{(2,299)}=215.488, \mathrm{P}<0.05\right)$. Parent supportiveness, locus of control and student gender were found not to have significant main effect on student achievement in mathematics. The results revealed a significant interaction effects were found not to be significant. 
Table 1: $\quad$ Summary of Analysis of Covariance of Students Achievement Scores by Gender, Locus of Control, Parent Supportiveness and Treatment

\begin{tabular}{|c|c|c|c|c|c|}
\hline Source of Variation & $\begin{array}{l}\text { Sum of } \\
\text { Square }\end{array}$ & DF & $\begin{array}{l}\text { Mean } \\
\text { Square }\end{array}$ & $\mathbf{F}$ & $\begin{array}{l}\text { Sing. of } \\
\text { F }\end{array}$ \\
\hline Covariates & 5.038 & 1 & 5.138 & 0.392 & 0.532 \\
\hline Pretest & 5.038 & 1 & 5.038 & 0.392 & 0.532 \\
\hline Main Effect & 5581.465 & 5 & 1116.263 & 86.860 & 0.000 \\
\hline Gender & 0.430 & 1 & 0.430 & 0.33 & 0.855 \\
\hline Locus of Control & 8.388 & 1 & 8.233 & .653 & 0.420 \\
\hline Parent Supportiveness & 19.942 & 1 & 19.942 & 1.552 & 0.214 \\
\hline Treatment & 5538.764 & 2 & 2769.382 & 215.488 & $0.000 *$ \\
\hline 2-Way Interaction & 12.213 & 9 & 14.357 & 1.117 & 0.351 \\
\hline Gender x L.O.C. & 0.202 & 1 & 0.202 & 0.016 & 0.900 \\
\hline Gender x Parent Sup. & 0.462 & 1 & 0.462 & 0.36 & 0.850 \\
\hline Gender $\mathrm{x}$ Treatment & 7.641 & 2 & 3.820 & 0.297 & 0.826 \\
\hline LOC x Parent Sup. & 0.619 & 1 & 0.619 & 0.048 & 0.826 \\
\hline LOC $\mathrm{x}$ Treatment & 46.999 & 2 & 23.500 & 1.829 & 0.163 \\
\hline Parent Sup. X Treatment & 74.658 & 2 & 37.329 & 2.905 & $0.054 *$ \\
\hline 3-Way Interaction & 181.1962 & 7 & 25.995 & 2.023 & 0.52 \\
\hline Gender x Loc x Par. Sup & 25.976 & 1 & 25.976 & 2.021 & 0.156 \\
\hline Gender $\mathrm{x}$ Loc $\mathrm{x}$ Treatment & 70.677 & 2 & 35.339 & 2.750 & 0.66 \\
\hline Gender x Parent Sup. X Treat. & 38.276 & 2 & 19.138 & 1.487 & 0.227 \\
\hline LOC $x$ Parent $X$ Treatment & 36.168 & 2 & 18.084 & 1.407 & 0.247 \\
\hline 4-Way Interaction & 6.287 & 2 & 3.143 & 0.245 & 0.783 \\
\hline \multicolumn{6}{|l|}{ Gender x Par. Sup LOC x } \\
\hline Treatment & 9.287 & 2 & 3.143 & 0.245 & 0.783 \\
\hline Explained & 5903.965 & 24 & 245.999 & 19.141 & 0.000 \\
\hline Residua & 3534.205 & 275 & 12.85233 & & \\
\hline Total & 9438.170 & 299 & 21.566 & & \\
\hline
\end{tabular}

*Denote Group significant at $\mathrm{P}<0.05$

The Multiple Classification Analysis, MCA (Table 2), reveals that the direction of increasing effect of instructional strategy (treatment) on mathematics achievement is conventional < peer tutoring alone < peer tutoring + teaching while the adjusted mean scores of the groups are 22.90, 30.13 and 33.02 respectively. The MCA in all reveals a multiple $\mathrm{R}$ squared value of 0.592 and beta value of $0.78,0.05,0.03$ and 0.01 for treatment, parent supportiveness, locus of control and gender respectively. Further analysis of the data on significant main effect of treatment on student achievement is reported in table 3 which shows that significant difference in students achievement exist between students exposed to conventional method and peer tutoring, conventional method and teacher _ peer tutoring as well as between those exposed to peer-tutoring and teaching + peer tutoring. There are indications that student achievement in mathematics could be significant improved by peer tutoring assisted instruction and peer tutoring respectively. 
Table 2: $\quad$ Multiple Classification Analysis (MCA) of Achievement Scores by Gender, Locus of Control, Parent Supportiveness and Treatment

\begin{tabular}{|c|c|c|c|c|c|}
\hline Variable + Category & $\mathbf{N}$ & $\begin{array}{l}\text { Unadjusted } \\
\text { Deviation }\end{array}$ & ETA & $\begin{array}{l}\text { Adjusted } \\
\text { for } \\
\text { independent } \\
\text { + Covariate }\end{array}$ & BETA \\
\hline \multicolumn{6}{|l|}{ Gender } \\
\hline 1. Girls & 137 & .05 & & 0.04 & \\
\hline \multirow[t]{2}{*}{ 2. Boys } & 163 & -.05 & & -0.03 & \\
\hline & & & 0.01 & & 0.01 \\
\hline \multicolumn{6}{|l|}{ Locus of Control } \\
\hline 1. External & 184 & -0.02 & & -0.17 & \\
\hline \multirow[t]{2}{*}{ 2. Internal } & 152 & 0.02 & & 0.17 & \\
\hline & & & 0.00 & & 0.03 \\
\hline \multicolumn{6}{|l|}{ Parent Supportiveness } \\
\hline 1. Low & 112 & 0.48 & & 0.34 & \\
\hline \multirow[t]{2}{*}{ 2. High } & 188 & -0.29 & & -0.20 & \\
\hline & & & 0.07 & & 0.05 \\
\hline \multicolumn{6}{|l|}{ Treatment } \\
\hline 1. Teaching + Peer Tutoring & 101 & 4.33 & & 4.45 & \\
\hline 2. Peer Tutoring & 99 & 1.43 & & 1.44 & \\
\hline 3. Conventional & 100 & -5.79 & & -5.92 & \\
\hline & & & 0.76 & & 0.78 \\
\hline Multiple R square & & & & & 0.592 \\
\hline Multiple R & & & & & 0.769 \\
\hline
\end{tabular}

Table 3: $\quad$ Scheffe Multiple Range Test of Achievement on Treatment

\begin{tabular}{|c|c|c|c|c|}
\hline & & \multicolumn{3}{|c|}{ Groups } \\
\hline Mean & Group & 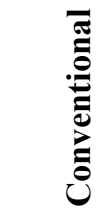 & 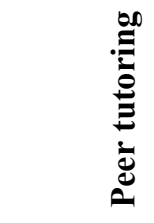 & 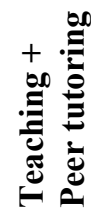 \\
\hline 22.9000 & Conventional & & & \\
\hline 30.1212 & Peer tutoring & * & & \\
\hline 33.0198 & Teaching + Peer tutoring & $*$ & $*$ & \\
\hline
\end{tabular}

Furthermore, the significant interaction effect of treatment and parent supportiveness is disentangled. This is illustrated graphically in Figure 1, which shows ordinal interaction. Students that were exposed to peer tutoring + teaching performed best irrespective of their parent supportiveness level and the students that were exposed to peer tutoring alone did better while the students that were exposed to conventional method performed least. The students that were exposed to conventional 
teaching, whose parent supportiveness is high did better than the students that were exposed to conventional method with low parent supportiveness.

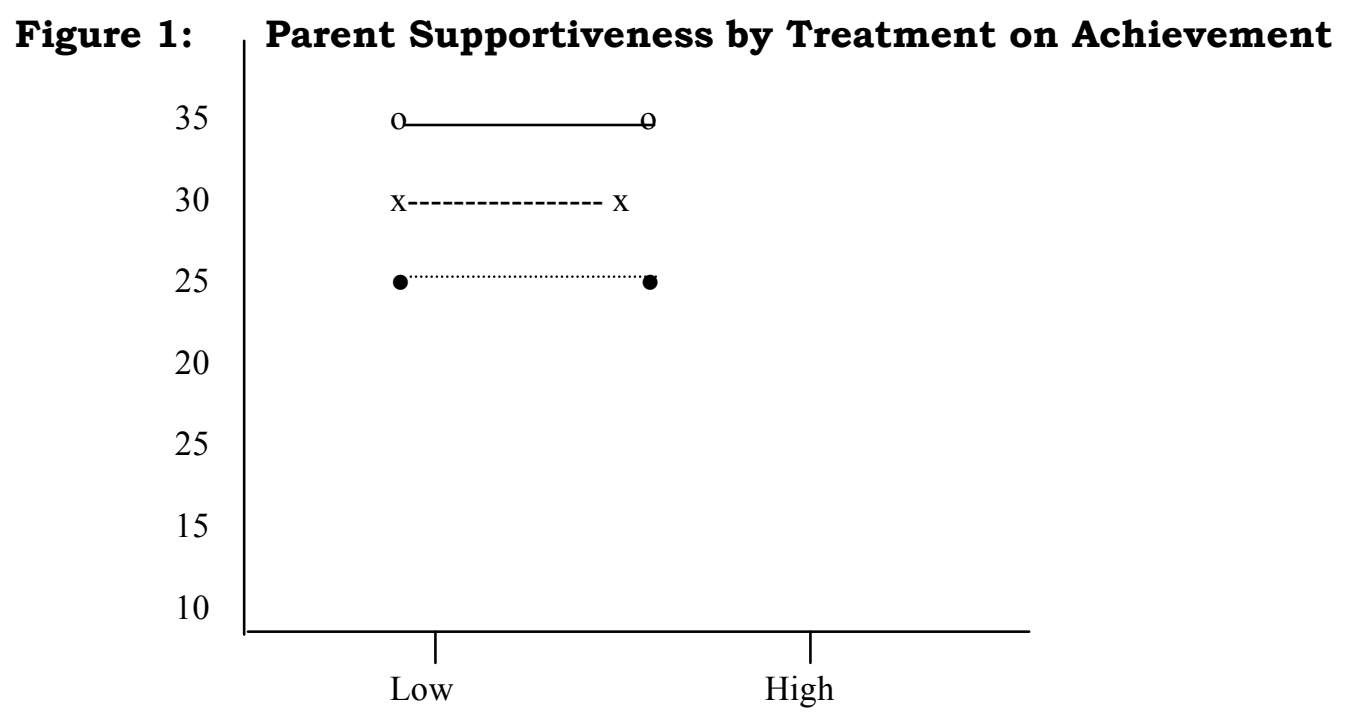

Where $\mathrm{x} \ldots \mathrm{x}$ is Peer tutoring; $\multimap$ is Teaching + Peer tutoring; and

$\bullet-----\bullet$ is Conventional method

\section{Discussion and Conclusion}

The main effect of peer tutoring, parent supportiveness locus of control and gender on students' achievement in Mathematics was only significant for the treatment and was not significant for parent supportiveness, locus of control and gender.

The significant main effect of treatment on student achievement in Mathematics agrees with the finding of Okebukola $(1984,1985)$ and Iroegbu (1998). The report on studies that assessed the effect of peer tutoring on academic achievement of college students have demonstrated that the instructional strategy benefit both the students being tutored and the tutor.

Frantuzzo et al. (1992) also support the use of peer tutoring for mathematics gains. Students that are exposed to peer tutoring in addition to the conventional method of teaching will gain more in mathematics and are likely to perform better than the students who are exposed to only conventional methods. The non-significant main effect of parent supportiveness, locus of control and gender is at variance with the view of Ojedele (1992), Igwe (1991) and Erinosho (1994) and tend to agree with Esho (1998) and Ross (1998).

The significant interaction effect of treatment and parent supportiveness on student achievement in secondary school mathematics revealed that when conventional method is used, the teacher should concentrate more on the students that have low parents supportiveness because the study shows 
that the peer tutoring plus teaching is also good for students from low parent supportiveness.

This tend to corroborate the finding of Miller and Kelly (1991) who also found no significant interaction between treatment and locus of control and between treatment and gender. The three-way and four-way interaction were found not to be significant on student academic achievement.

In all, the independent variables (treatment, parent supportiveness, student locus of control) and moderator variable (gender), when taken together could be used to explain $59.2 \%$ of variation in secondary school mathematics achievement of the students a level of explanation that is considered significant $(\mathrm{P}<0.01)$. The order of the contributions of the variables to the explanation is treatment $(62.4 \%)$ followed by parent supportiveness $(0.25 \%)$, locus of control $(0.09 \%)$ and the least is gender $(0.01 \%)$.

In the light of all the results and the associated discussion, we share the view that peer tutoring assisted instruction has the potential to improve students' achievement in mathematics and it is thus suggested that practicing mathematics teachers in secondary schools should use peer tutoring as an integral part of instructional strategy in mathematics classroom. The nature of the significant interaction effect of treatment and parent supportiveness on mathematics achievement provides the empirical basic for suggesting the use of the treatment in classrooms irrespective of students' level of parent supportiveness. The treatment could also play a remedial role for mathematics students who are disadvantage because of their low parent supportiveness. It is hoped that the implementation of these recommendations would lead to our ultimate goal of improved secondary students' enrolment in science courses in higher institution as well as their performance in mathematics at the secondary school level.

\section{References}

Adepoju J.A. (1991) 'Factors and Problems in the Teaching and Learning of Mathematics in Nigeria Schools'. National School curriculum Review Conference Proceedings. Lagos; Federal Ministry of Education.

Akinsola, M.K. (1999). 'Effects of Instruction on Students Performance on Knowledge, Comprehension and Sand Application Tasks in Mathematics'. African Journal of Educational Research 5(1), 94-99

Annis; L.E. (1982). The Cognitive Benefit of Peer Tutoring. Paper Presented at the Meeting of the American Educational Research Association, New York.

Annis, L.E. (1983). 'The Process and Effects of Peer Tutoring' Human Learning. 2, 39-47

Bargh; J.a. and Schul, Y.I. (1980) 'Cognitive Benefit of Teaching'. Journal of Educational Psychology 72, 593-604

Erinosho,S.Y. (1994) Perspective on Women in Science and Technology in Nigeria, Ibadan, Sam-Bookman 
Eso, O.T. (1998) Assessment Procedures and Locus of Control Paradigm as Determinant of Students Achievement in Integrated Science. (Ph.D. Research Proposal) University of Ibadan

Fajemidagba, O. (1996) School Mathematics and Mass Education in Nigeria; the Result of an Exploratory Study in Samuel Ayodele (ed). Education in the Service of Humanity.

Frantuzzo J.W. king, J.A. and Heller L.R, (1992) 'Effects of Reciprocal Peer Tutoring on Mathematics and School Adjustment: A Component Analysis'. Journal of Education Psychology 84, 331-339

Igwe, G. O. (1991) Impact of Behavioral Objectives, Cognitive Entry Behavior and Locus of Control Paradigm on Student Learning Outcomes. (Unpublished Ph.D Thesis) University of Ibadan

Iroegbu (1998) Problem based learning, numerical ability and gender as determinant of Achievement, Problem Solving Line-Graphing Skills in Senior Secondary Physics in Ibadan. (Unpublished Ph.D. Thesis) University of Ibadan

Lambiotte, J.G. Dansereau, D.f., O’Donnel, A.M. Young, M.D. Skars, L.P. Hall and Rocklin, T.R. (1987) 'Manipulating Cooperative Scripts for Teaching and Learning', Journal of Education psychology, 79, 424-430

Miller, D.L. and Kelly, M. (1991) 'Intervention for Improving Homework Performance: A Critical Review', School Psychology Quarterly 6, 174-185

Ojedele P.K. (1992) Influence of Parental Involvement on School Performance in Oyo State. (Unpublished Ph.D. Thesis), Ibadan: University of Ibadan.

Okebukonla, P.A. O (1984) Effects of Cooperative Competitive and Individualistic Laboratory Interaction Pattern on Students Performance in Biology. (Unpublished Ph.D. Thesis), Ibadan: University of Ibadan

Okebukonla, P.A. (1985) The Relative Effectiveness of Cooperative and Competitive Interaction Techniques in Strengthening Student's Performance in Science Classes. Science Education 69, 501-509

Onocha, C.A. Okpala P.N. and Offorma, G. (1995) Education of Women and Girls: Study of Equity in Eastern Nigeria. A study Commissioned by the Regional Office of UNESCO/BREDA in AFRICA, Dakar, Senegal 101

Ross. J. (1998) Improving Social-environmental Studies Problem Solving Through Cooperative Learning. American Educational Research Journal 25(4) 573-691

Slavin, R. (1990) 'Cooperative Learning'. In C. Rogers and P. Kutnick (Ed). The Social psychology of the Primary School. London: Routledge, 226246 